\title{
Improvement of Ips typographus catches in pheromone trap barriers by altering of sex assigned pheromone blends
}

\author{
Miroslav Blaženec ${ }^{1 *}$, Andrej Majdák ${ }^{1}$, Rastislav Jakušs ${ }^{1,2}$ \\ ${ }^{1}$ Institute of Forest Ecology, Slovak Academy of Sciences, \\ L. Štúra 2, 96001 Zvolen, Slovakia \\ ${ }^{2}$ Czech University of Life Sciences, Faculty of Forestry and Wood Sciences, \\ 16500 Prague 6 - Suchdol, Czech Republic
}

\begin{abstract}
BlažENEC, M., MAJDÁK, A., JAKUŠ, R., 2021. Improvement of Ips typographus catches in pheromone trap barriers by altering of sex assigned pheromone blends. Folia Oecologica, 48 (1): 25-34.

The present study was based on the idea of a pheromone trap barrier with alternating dispensers releasing different pheromone mixtures that affect males and females differently. We tested the possibility of increasing the catch efficacy of pheromone trap barriers by altering the pheromone mixture with low levels of cis-Verbenol (cV, targeting males, $\mathrm{BM}$ ), the mixture with high levels of $\mathrm{cV}$ (targeting females, $\mathrm{BF}$ ) and the pheromone mixture with intermediate levels of $\mathrm{cV}$ (SL). In addition, we were interested in lowering the dispersion of attracted bark beetles, especially males, which reduces the risk of attack on trees in the surroundings. Significant highest absolute and relative catch was found in the catch of the combination BM-BF, which was 2.2-fold higher than the catch of the control barrier treated with commercial IT Ecolure baits (Fytofarm, Slovakia). At the same time, the lowest dispersal in the surroundings of the barrier with the combination BM-BF was found, which was 2.5 -fold lower than in the control barrier. The performance of the BM-BF combination of mixtures was proved in a field trial experiment where the total season catch of the part of the barrier treated with BM-BF dispensers caught 1.5-fold more beetles during the season than the control part treated with IT Ecolure dispensers. Furthermore, the results confirm that the performance of the combination of low levels of $\mathrm{cV}$ (targeting males) and high levels of $\mathrm{cV}$ (targeting females) is complemented by the desired reduced dispersion around the barrier, which reduces the risk of attack on trees in the surroundings.
\end{abstract}

\section{Keywords}

dispersion around the barrier, Ips typographus, pheromone trap barrier

\section{Introduction}

Barriers of pheromone traps are used as a part of integrated pest management against Ips typographus (L.) (NIEMEYER, 1997; JAKUŠ, 1998), the most important pest in spruce (Picea abies [L.] Karst.) in Europe (SEIDL et al., 2016). The barriers represent one of the possibilities for the protection of spruce stands, and they can protect the selected stand by significantly lowering the primary beetle attack rate. The use of pheromone trap barriers for the protection of spruce stands has been discussed, in conjunction with the method's advantages and risks, by several authors (VITÉ, 1989; NIEMEYER, 1997; JAKUŠ, 1998). ZAHRADNÍKOVÁ and ZAHRADNÍK (2017) showed that increasing trap efficiency simply by increasing the release rate of the pheromone is not effective. GALKo et al. (2016) showed possibilities of increasing trapping efficiency by improving trap design.

The critical point is that high concentrations of pheromones may result in attacks on trees surrounding the pheromone sources. The problem of bark beetle infestations around traps can be partially mitigated by decreasing distances between traps (NIEMEYER, 1997) or 
by increasing the trap size (VAuPEL and DubBel, 1985). I. typographus males initiate the attack and the colonisation of trees; consequently, the male catch is crucial for the overall efficacy of pheromone trap barriers. High concentrations of pheromones attract both sexes equally from a long distance (SCHLYTER et al., 1987a), even though males are reported to be more sensitive to the pheromone (DiCKens, 1981).

Previous studies oriented on increasing male catch in pheromone trap barriers used differing approaches with different levels of effectiveness. JAKUŠ and BLAŽENEC (2002) suggested using a combination of traps baited with dispensers having two different release levels of (4S)-cisverbenol $(\mathrm{cV})$ in the pheromone mixtures in order to achieve higher catches of males. An increase in the $\mathrm{cV}$ release rate with constant 2-methyl-3-buten-2-ol (MB) increases the number of beetles caught; however, the proportion of males is reduced when higher doses of $\mathrm{cV}$ are used in the pheromone mixtures (SCHLYTER et al., 1987b). JAKUŠ and BLAŽENEC (2003) show that the efficacy of pheromone trap barriers with alternating dispensers, having two different release levels of $\mathrm{cV}$ in the pheromone blends, can be changed by adding (-)- $\alpha$-pinene. The number of beetles captured by traps baited with a low-level release of $\mathrm{cV}$ was increased by adding (-)- $\alpha$-pinene. However, adding (-)- $\alpha$-pinene did not increase the catches of traps containing high releases of $\mathrm{cV}$. Further improvement of pheromone trap barriers is possible using compounds synergistic with the basic I. typographus pheromone mixture of $\mathrm{cV}$ and MB. REDDEMANN and SCHOPF (1996) and GossENAUER-MAROHN (1988) studied the significance of the primary attraction of monoterpenes on the spruce bark beetle and their influence on the attractiveness of the commercially manufactured pheromones or traptrees. According to RedDEMANN and Schopf (1996), supplementing (-)- $\alpha$-pinene with $(+)$-limonene resulted in a significant increase in trap catch (by 81\%) with lures that were one-third filled with Pheroprax bait with the following chemical composition: $\mathrm{MB}, \mathrm{cV}$, Ipsdienol in a ratio 96.08:3.56:0.36. This approach was further tested in the field by Niemeyer and WatzeK (1996), but they could not confirm a statistically significant increase in the catch.

BLAŽENEC and JAKUŠ (2009) compared two different strategies to increase the catches of I. typographus, particularly males, in pheromone-baited traps. The first of these strategies, the barrier approach, used alternating pheromone blends, targeting males and females specifically, in closely-spaced traps forming a barrier around forest stands. The second strategy, the single trap approach, used widely-spaced traps, all baited with the same lure that was intended to trap the highest possible numbers of males without compromising trapping of females. Currently, the possibilities of further improvement of spruce stand protection with semiochemicals are limited. One possible way could be the identification of new active compounds, acting as $I$. typographus attractants and anti-attractants (SCHIEBE et al., 2012, 2019) and the combination of pheromone trap barriers with anti-attractants-treated forest stands (SCHIEBE et al., 2011; JAKUŠ et al., 2011).
Our experiment was based on the idea of a pheromone trap barrier with alternating dispensers releasing different pheromone mixtures that affect males and females differently. The aim of the present study was to test the possibility of increasing the efficacy of pheromone trap barriers by altering the pheromone mixture with low levels of $\mathrm{cV}$ (targeting males), the mixture with high levels of $\mathrm{cV}$ (targeting females), and the pheromone mixture with intermediate levels of cV. BLAŽENEC and JAKUŠ (2009) optimised the mixtures with higher attractiveness for males (BM) and the mixture with higher attractiveness for females (BF) for use in pheromone trap barriers, and mixtures with higher attractiveness for both sexes for use in single standing traps (SL). These mixtures were combined in the pheromone trap barriers in order to optimise the pheromone trap barrier for the best capture, as well as the lowest dispersion of attracted bark beetles in the surroundings of the barriers.

\section{Materials and methods}

\section{Pheromone baits}

Synthetic pheromone baits from Fytofarm Ltd. (Bratislava, Slovakia) were used. Chemicals, their purities and sources are presented in Table 1. The chemical composition of the pheromone baits used in the experiment is shown in Table 2. The control was a commercial dispenser IT Ecolure from Fytofarm Ltd. (Bratislava, Slovakia). Special wickaluminium foil protected dispensers from Fytofarm Ltd. (VARKONDA, 1996) were used. In the case of mixture BF, all compounds were filled in one dispenser and, similarly, in the control IT Ecolure. Double-dispensers were used for $\mathrm{BM}$ and SL mixtures. In one bag, the monoterpenes were separated from other compounds due to lower boiling temperature, and another type of wick for better regulation of release was used. In the second bag remained other compounds. The average release rate of mixtures from both type of dispensers was about $50 \mathrm{mg}^{\text {day }}{ }^{-1}$ (Fytofarm Ltd.) in field conditions. All dispensers were filled with $3 \mathrm{ml}$ of pheromone mixture.

\section{Pheromone traps}

Cross-type pheromone traps, Ecotrap from Fytofarm Ltd., were used. This universal, selective and omnidirectional pheromone trap is made from black plastic and has an effective size of $5,550 \mathrm{~cm}^{2}$.

\section{Experiment design and locality \\ Pheromone barrier improvement experiment}

The experiment was conducted in four pheromone trap barriers. The layout of the pheromone trap barriers used in this experiment is shown in Fig. 1. The distance between two neighbouring traps was approximately $12 \mathrm{~m}$, and the distance between two neighbouring barriers was at least $20 \mathrm{~m}$. The distance between active pheromone traps and the forest edge was about $15 \mathrm{~m}$. 
Table 1. Compounds, purity, and source in pheromone baits tested in the experiments

\begin{tabular}{ccc}
\hline Compound & Purity & Source \\
\hline (4S)-cis-verbenol & $\geqq 98 \%$ & Fytofarm Ltd. (Slovakia) \\
2-methyl-3-buten-2-ol & $\geqq 98 \%$ & FLUKA AG (Switzerland) \\
$(-)$ - $\alpha$-pinene & $\geqq 98 \%$ & FLUKA AG (Switzerland) \\
$(+)-$ limonene & $\geqq 90 \%$ & FLUKA AG (Switzerland) \\
1-methoxy-2-propanol & $\geqq 98 \%$ & SH-Chem (Slovakia) \\
$($ S)-(+)-ipsdienol & $\geqq 95 \%$ & Bedoukian Research, Inc. (USA) \\
\hline
\end{tabular}

Table 2. Chemical composition of pheromones used in the experiment

\begin{tabular}{ccccc}
\hline Pheromone bait: & BM & BF & SL & IT Ecolure* \\
\hline Bait composition (\%) & & & & $\leq 85.0$ \\
2-methyl-3-buten-2-ol & 64.1 & 90.1 & 85.8 & $\geq 3.2$ \\
$(4 S)$-cis-verbenol & 0.9 & 9.0 & 3.3 & - \\
$(-)$ - $\alpha$-pinene & 0.9 & - & 9.9 & $\geq 0.4$ \\
$(+)-$ limonene & 3.5 & 0.9 & - & - \\
(S)-(+)-ipsdienol & - & - & 0.9 & - \\
1-methoxy-2-propanol & - & - & - & $\geq 3.6$ \\
ethanol & - & - & & $\geq 3.8$ \\
spruce oil & - & &
\end{tabular}

*Chemical composition estimated from original label.

Every barrier consisted of four active pheromone traps and four passive traps were located in its surroundings. In the active traps, combinations of pheromone baits were tested, and the passive traps were used for catching Ips typographus individuals dispersed in the surrounds of the barriers.
We tested three combinations of pheromone baits that were altered in the pheromone traps of individual barriers: BM-BF, BM-SL, and BM-IT Ecolure. One barrier was treated only with IT Ecolure (control barrier).

The positions of the combination of the baits were changed according to the randomised experimental design

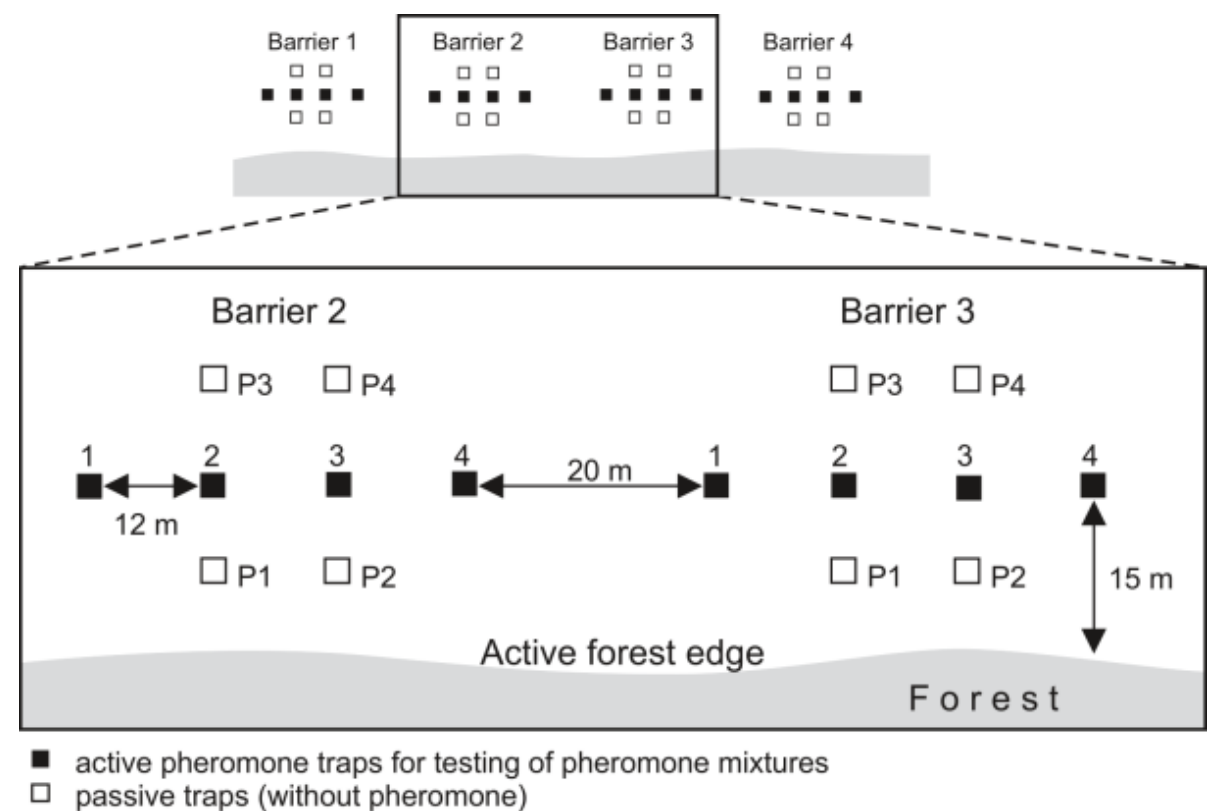

Fig. 1. The layout of experimental pheromone trap barriers used in pheromone barrier improvement experiment. 
(BYERS, 1991) between the barriers after each collecting of beetles and were rotated six times. The time between the particular trap check and beetle collection depended on the weather but was no longer than one week. Beetles were collected from all active and passive traps. However, catches from marginal active traps (traps 1 and 4, Fig. 1) were not further processed regarding their possible affection of neighbouring barriers, even if these traps were essential for the correct working of the pheromone traps barriers.

The experiments were conducted in 80-90-year-old spruce stands situated in the Pol'ana Mountains in central Slovakia at altitudes of about $750 \mathrm{~m}$ above sea level on the southwest slopes in clear-cuts after salvage cutting. The period of testing was from June to August 2002. This period was used in order to avoid spring swarming and, in particular, the higher proportion of males during spring swarming. In using this period, it is assumed that the negative impact on the results due to the applied experimental design was low.

\section{Verification of improved barrier}

Part of a long pheromone trap barrier usually used in forest protection was treated with altered experimental pheromone baits $\mathrm{BM}$ and $\mathrm{BF}$. Other parts of the barrier treated with commercial IT Ecolure bait were used as a control. In total, 29 traps were treated with BM and 29 traps with BF, and 58 traps treated with IT Ecolure were used as control.

The experiments were conducted in more than 120-year-old spruce stands situated in the eastern part of the High Tatra Mountains in east Slovakia at altitudes of about $1,250 \mathrm{~m}$ above sea level on the SWW slopes in clearcuts after salvage cutting. The period of testing was from June to August 2004.

\section{Laboratory processing}

Beetles were dissected and separated according to the sex.

\section{Statistics}

\section{Pheromone barrier improvement experiment}

From the active traps, only the two traps in the middle of each barrier (marked as 2 and 3, Fig. 1) were further processed, and from passive traps all traps were further processed and statistical analysis concerns only these traps. The absolute and relative catches were statistically analysed. The relative catch was the basis for results interpretation and the absolute catch was used as additional information to the relative catch. Conversion of absolute to relative catches enabled us to eliminate the effect of different time intervals and weather conditions corresponding to the individual replications and to emphasize the differences between the baits. The relative catch for one trap in the barrier in a particular replication was calculated as a percentage of the total catch in all active pheromone traps (traps 2 and 3, Fig. 1) in that particular replication. The relative catch for one barrier in a particular replication was calculated as a percentage of the total catch in all active pheromone traps (traps 2 and 3,
Fig. 1) in that particular replication. The relative catch for passive traps (two) near the concrete mixture in the barrier $(\mathrm{P} 1+\mathrm{P} 3$ or $\mathrm{P} 2+\mathrm{P} 4$, Fig. 1$)$ in a particular replication was calculated as a percentage of the total catch in all passive traps in that particular replication. The relative catch for a group of passive traps (four) in the surrounds of the barrier in a particular replication was calculated as a percentage of the total catch in all passive traps in that particular replication. The relative catch was calculated for males and females.

The percentage of catch in passive traps near the concrete mixture in the barrier relative to the catch in the active trap with this mixture in a particular replication was calculated from the total catch in the active trap and the two passive traps $(\mathrm{P} 1+\mathrm{P} 3$ or $\mathrm{P} 2+\mathrm{P} 4$, Fig. 1$)$ in that particular replication. The percentage of catch in a group of passive traps (without pheromone) from the catch in the barrier in a particular replication was calculated from the total catch in two active traps in the middle of the barrier and four passive traps in the surrounds of the barrier in that particular replication (Fig. 1). Females and males were considered separately.

Assumptions for the use of parametric statistics were tested (Shapiro-Wilk test and Levene test, UNDERWOOD, 2001). Arcsin square root transformation of the data was used. For the data that complied with the assumptions, analysis of variance (ANOVA) followed by Duncan's multiple range test was performed. For the data that did not comply with the assumptions, the nonparametric Kruskal-Wallis test (multiple comparison) followed by pairwise comparison were used to find the differences between the groups.

\section{Verification of improved barrier}

In this experiment, we used 29 alternated bait combinations BM-BF in one part of the pheromone trap barrier (58 traps), and 29 pairs of IT Ecolure baits in another part of the barrier (58 traps) served as controls. Both sets of 29 pairs were considered as statistical replicates. The total catch in the barrier from the whole period was subject to statistical analyses. Assumptions for the use of parametric statistics were tested (Shapiro-Wilk test and Levene test, UNDERWOOD, 2001). Arcsin square root transformation of the data was used and analysis of variance (ANOVA) was performed.

\section{Results}

\section{Pheromone barrier improvement experiment}

Over the whole pheromone barrier improvement experiment, 23,799 specimens of Ips typographus were caught in active traps in all barriers. In passive traps in the surrounds of the barriers, 358 specimens were caught.

\section{Active pheromone traps}

ANOVA and Duncan's multiple range tests show a statistically significant effect (Table 3a) in the absolute and relative catch of females and males between individual 
Table 3. ANOVA or Kruskal-Wallis test results, following results from Levene's test and the Shapiro-Wilk W test: a) Over the whole pheromone barrier improvement experiment, 23,799 specimens of Ips typographus were caught in active traps and 358 specimens were caught in passive traps; b) Over the whole verification of improved barrier experiment, 753,615 specimens were caught

\begin{tabular}{|c|c|c|c|c|c|c|c|c|}
\hline \multirow{2}{*}{$\begin{array}{l}\text { a) Pheromone barries } \\
\text { improvement } \\
\text { experiment }\end{array}$} & \multirow[b]{2}{*}{ Sex } & \multicolumn{2}{|c|}{ Levene test } & \multicolumn{2}{|c|}{ Shapiro-Wilk test } & \multicolumn{3}{|c|}{ ANOVA } \\
\hline & & $\mathrm{F}$ & $\mathrm{P}$ & $\mathrm{W}$ & $\mathrm{P}$ & $\mathrm{F}$ & $\mathrm{df}$ & $\mathrm{P}$ \\
\hline \multicolumn{9}{|l|}{ Absolute catch in: } \\
\hline \multirow[t]{2}{*}{ active traps } & 우우 & 1.01 & 0.44 & 0.96 & 0.23 & 2.99 & 7 & 0.01 \\
\hline & $\hat{\partial} \widehat{\partial}$ & 0.68 & 0.68 & 0.98 & 0.74 & 3.59 & 7 & $<0.01$ \\
\hline \multirow[t]{2}{*}{ active barriers } & 우우 & 0.62 & 0.61 & 0.93 & 0.10 & 3.47 & 3 & 0.03 \\
\hline & $\hat{\partial}$ & 1.58 & 0.23 & 0.95 & 0.29 & 5.06 & 3 & $<0.01$ \\
\hline \multirow[t]{2}{*}{ passive traps } & 우우 & 1.08 & 0.39 & 0.96 & 0.27 & 0.76 & 7 & 0.62 \\
\hline & केत & 1.39 & 0.24 & 0.95 & 0.13 & 0.29 & 7 & 0.95 \\
\hline \multirow[t]{2}{*}{ passive barriers } & 우우 & 1.46 & 0.25 & 0.98 & 0.88 & 0.62 & 3 & 0.61 \\
\hline & $\hat{\partial} \sigma^{\lambda}$ & 0.53 & 0.67 & 0.95 & 0.32 & 0.28 & 3 & 0.83 \\
\hline \multicolumn{9}{|l|}{ Relative catch in: } \\
\hline \multirow[t]{2}{*}{ active traps } & 우우 & 0.71 & 0.67 & 0.95 & 0.06 & 4.26 & 7 & $<0.01$ \\
\hline & $\widehat{\partial}$ & 1.22 & 0.32 & 0.98 & 0.82 & 5.24 & 7 & $<0.01$ \\
\hline \multirow[t]{2}{*}{ active barriers } & 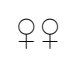 & 0.17 & 0.92 & 0.97 & 0.79 & 8.33 & 3 & $<0.01$ \\
\hline & $\hat{\partial}$ & 0.56 & 0.65 & 0.96 & 0.54 & 12.29 & 3 & $<0.01$ \\
\hline \multirow[t]{2}{*}{ passive traps } & 우우 & 1.52 & 0.19 & 0.95 & 0.18 & 1.01 & 7 & 0.43 \\
\hline & $\hat{\partial} \widehat{\partial}$ & 1.61 & 0.16 & 0.96 & 0.31 & 0.33 & 7 & 0.93 \\
\hline \multirow[t]{4}{*}{ passive barriers } & 우우 & 1.11 & 0.37 & 0.97 & 0.68 & 0.74 & 3 & 0.53 \\
\hline & $\hat{\partial} \widehat{\partial}$ & 2.98 & 0.06 & 0.96 & 0.47 & 0.38 & 3 & 0.76 \\
\hline & & & & & & \multicolumn{3}{|c|}{ Kruskal-Wallis test } \\
\hline & & & & & & $\mathrm{H}$ & $\mathrm{df}$ & $\mathrm{P}$ \\
\hline \multicolumn{9}{|l|}{$\%$ of catch in: } \\
\hline \multirow[t]{2}{*}{ passive traps } & 우우 & 2.45 & 0.04 & 0.86 & 0.01 & 9.20 & 7 & 0.24 \\
\hline & $\hat{\partial}$ & 1.89 & 0.09 & 0.84 & 0.01 & 7.46 & 7 & 0.38 \\
\hline \multirow[t]{2}{*}{ passive barriers } & 우우 & 0.75 & 0.54 & 0.96 & 0.43 & 7.83 & 3 & 0.04 \\
\hline & $\hat{\partial} \hat{O}$ & 1.01 & 0.41 & 0.86 & 0.01 & 1.56 & 3 & 0.67 \\
\hline \multirow{2}{*}{\multicolumn{2}{|c|}{$\begin{array}{l}\text { b) Verification of } \\
\text { improved barrier }\end{array}$}} & \multicolumn{2}{|c|}{ Levene test } & \multicolumn{2}{|c|}{ Shapiro-Wilk test } & \multicolumn{3}{|c|}{ ANOVA } \\
\hline & & $\mathrm{F}$ & $\mathrm{P}$ & $\mathrm{W}$ & $\mathrm{P}$ & $\mathrm{F}$ & $\mathrm{df}$ & $\mathrm{P}$ \\
\hline \multicolumn{9}{|l|}{ Absolute catch in: } \\
\hline trap pairs & & 1.54 & 0.18 & 0.96 & 0.09 & 5.71 & 1 & 0.02 \\
\hline
\end{tabular}

mixtures used in combinations in barriers (Fig. 2a, c) and also between the combinations of mixtures used in barriers (Fig. 2b, d).

The absolute catch had nearly a similar pattern to that of the relative catch. The highest relative catch of females was in the trap baited with the mixture BF from the combination $\mathrm{BM}-\mathrm{BF}$ in the barrier, and the highest relative catch of males was in the trap baited with the mixture $\mathrm{BM}$ also from the combination $\mathrm{BM}-\mathrm{BF}$ in the barrier. The lowest relative catch in all tested variables was in the trap with one of the IT Ecolure baits in the control barrier IT-IT. In all combinations, the mixture BM had the highest relative catch of males (Fig. 2c).

In the case of the relative catch of combinations of mixtures, the highest catch of females and males was in the combination of mixtures BM-BF. The relative catch of this combination was nearly twice that of the control barrier with IT Ecolure (IT-IT). The relative catch of combinations of mixtures BM-IT and BM-SL was slightly higher than IT-IT (Fig. 2d). In the absolute catch of combinations of mixtures, the catch of the combination BM-BF was 2.2-fold higher 

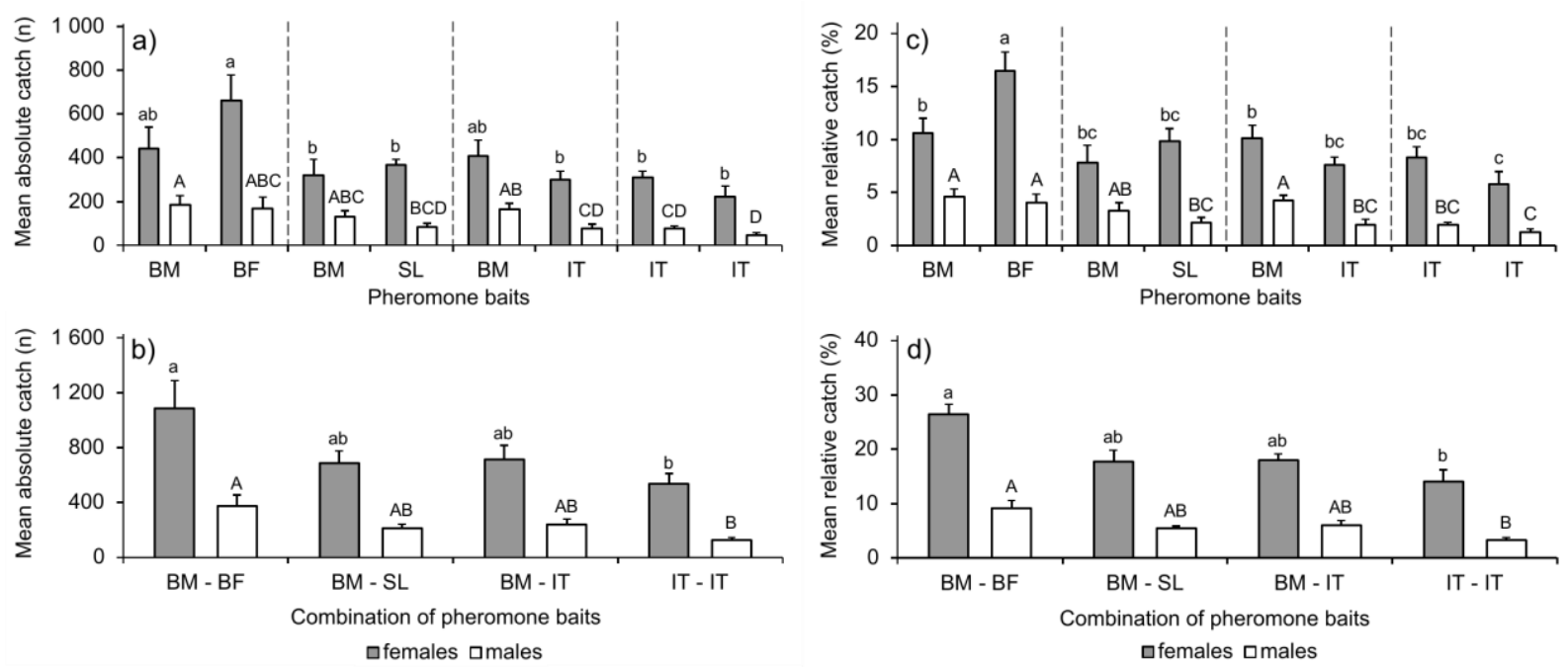

Fig. 2. Mean catch ( \pm SE) of Ips typographus: a) absolute catch of individual pheromone baits used in the barrier and b) absolute catch of combination of baits used in the barrier; c) relative catch of individual pheromone baits used in the barrier and d) relative catch of combination of baits used in the barrier. Bars with the same letter are not different, according to Duncan's multiple range test. Females and males are considered separately. Over the whole experiment, 23,799 specimens of Ips typographus were caught in active traps.

than the catch of the control barrier IT-IT, and 1.5-fold higher than the combinations of mixtures BM-IT and BM-SL.

\section{Passive traps}

ANOVA did not show any significant effect (Table 3a) in the absolute and relative catch in passive traps (Fig. 3a, c) or in the group of passive traps (Fig. 3b, d) in all tested variables.

The highest absolute catch of females was in the passive traps near one of the IT Ecolure baits in the control barrier IT-IT. The highest absolute catch of males was in passive traps near the mixture SL in the combination of mixtures BM-SL (Fig. 3a). However, the highest relative catch of females was near the mixture $\mathrm{BF}$ in the combination $\mathrm{BM}-$ $\mathrm{BF}$, and the highest relative catch of males was near one of the IT Ecolure baits in the control barrier IT-IT (Fig. $3 \mathrm{c})$. Thus, the absolute and relative captures do not show a similar pattern. The lowest relative catch of females was in passive traps near the mixture BM in the combination $\mathrm{BM}-\mathrm{BF}$. The lowest relative catch of males was in passive traps near the other IT Ecolure bait in the control barrier (Fig. 3c).

In the case of groups of passive traps, the highest absolute catch of both sexes was in the group $\mathrm{P}(\mathrm{BM}-\mathrm{SL})$ in the surrounds of the barrier with the combination of mixtures BM-SL (Fig. 3b). The highest relative catch of females was in the group $\mathrm{P}(\mathrm{BM}-\mathrm{BF})$, and males in the group $\mathrm{P}(\mathrm{BM}-\mathrm{SL})$. The lowest relative catch of females was in the group $\mathrm{P}(\mathrm{BM}-\mathrm{IT})$ in the surrounds of the barrier with the combination of mixtures BM-IT, and for males was in the group $\mathrm{P}(\mathrm{BM}-\mathrm{BF})$ (Fig. 3d).

Although this trend is not significant in connection with the results from active traps and barriers, we observe a more substantial proportion of captured males in baited traps, especially with a mixture of BM and, at the same time, a smaller number of males in passive traps near
BM. Since in I. typographus the males start the attack on trees, the result that the mixture, or their combination in the barrier, attracts them to the trap, and reduces their avoidance of the traps and dispersion in the surroundings, is highly important.

\section{Percentage of catch in passive traps from the catch in active traps}

The percentage of the catch in passive traps relative to the catch in the active traps indicates a ratio between the performance of mixtures in baited traps in terms of their catching ability and the possible unwanted dispersion of untrapped beetles around the traps or barriers. The Kruskal-Wallis test showed a significant difference (Table 3a) in the mean female percentage of catch in passive traps both near the concrete mixture in the barrier (Fig. 4a) and near a combination of baits used in the barrier (Fig. 4b).

The lowest percentage of the catch of females and males near the concrete mixture in the barrier was found in the mixture BM in the combination BM-BF. On the contrary, the highest percentage of the catch of both sexes was found for one of the IT Ecolure baits in the control barrier IT-IT, whereas the females differed significantly. This same trend was found even in combinations of mixtures in barriers when the lowest percentage of catches in passive traps was for both sexes in the combination $\mathrm{BM}-\mathrm{BF}$, which was 2.5-fold lower than the combination of IT Ecolure baits in the control barrier.

In addition, the results from the percentage of the catch in passive traps relative to the catch in the active traps confirm that the performance of the combination of BM and BF mixtures is complemented by the desired reduced dispersion around the barrier, which reduces the risk of attack on trees in the surroundings. 

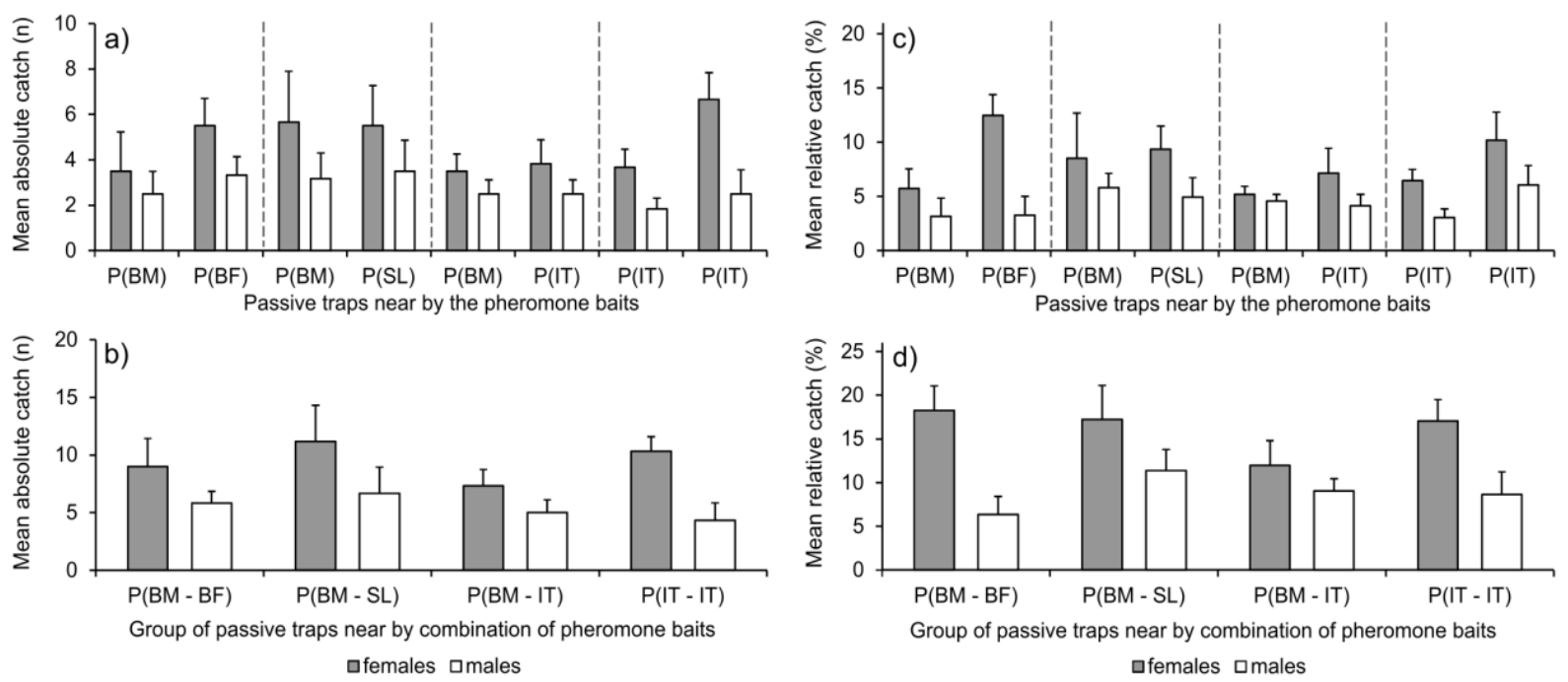

Fig. 3. Mean catch $( \pm \mathrm{SE})$ of Ips typographus: a) absolute catch in passive traps near the concrete mixture in the barrier,

b) absolute catch in groups of passive traps in the surrounds of pheromone trap barriers used for testing of different combinations of mixtures, c) relative catch in passive traps near the concrete mixture in the barrier and d) relative catch in groups of passive traps in the surrounds of pheromone trap barriers used for testing of different combinations of mixtures. Females and males are considered separately. Over the whole experiment, 358 specimens of Ips typographus were caught in in passive traps.
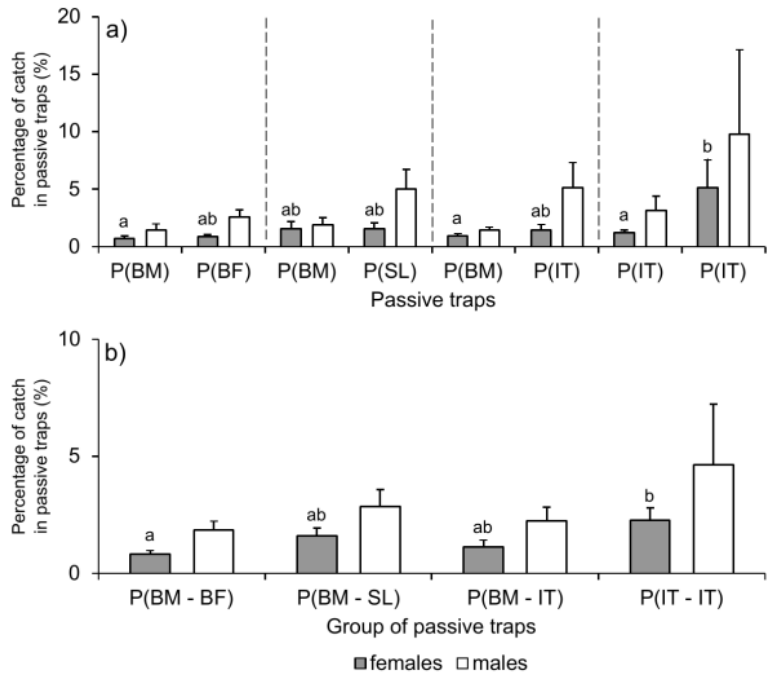

Fig. 4. Mean percentage of Ips typographus catch ( \pm SE): a) in passive traps near the concrete mixture in the barrier from the catch in the active trap with this mixture, b) near a combination of baits used in the barrier. Bars with the same letter are not different, according to Kruskal-Wallis test pairwise comparison. Females and males are considered separately.

\section{Verification of improved barrier}

Over the whole verification of improved barrier experiment, 753,615 specimens of Ips typographus were caught.

We found a significant difference between the mean catches in the trap pairs treated with BM-BF dispensers with values of 7,785 \pm 822 (mean $\pm \mathrm{SE}$ ) and IT Ecolure dispensers with values of 5,207 \pm 322 (Table 3b, Fig. 5a). The same pattern is also observed in the total season catch (Fig. 5b) where the part of the barrier treated with BM-BF dispensers caught 1.5 -fold more beetles during the season than the part treated with IT Ecolure dispensers.

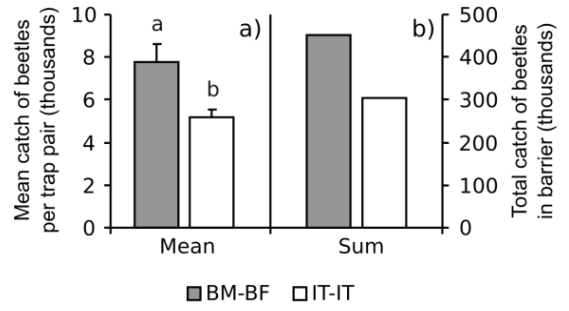

Fig. 5. Mean $( \pm \mathrm{SE})$ and total catch in trap pairs with BM-BF dispensers and traps with IT Ecolure dispensers: a) mean catch and b) total catch. Differences in mean catch are marked according to ANOVA results. Over the whole experiment, 753,615 of Ips typographus specimens were caught.

\section{Discussion}

In improving the barriers of pheromone traps, we combined optimized compounds with higher attractiveness for males $(\mathrm{BM})$, with higher attractiveness for females (BF), and a universal mix for both genders (SL) from BLAŽENEC and JAKUŠ (2009), as well as commercial pheromone preparation IT Ecolure. When evaluating the results of the improving of pheromone traps barriers, we considered both the behavior of individual mixtures in combination with others and the overall functioning of the barrier. Comparison of results of relative trapping of individual pheromone mixtures in active traps confirmed the results of optimization of pheromone mixtures (BLAŽENEC and JAKUŠ, 2009) and the theoretical assumptions on which we optimized these mixtures (SCHLYTER et al., 1987a; Schlyter et al., 1987b; JaKuš and BlažEneC, 2002; JAKUŠ and BLAŽENEC, 2003). Results of our experiment were confirmed in pheromone trap barriers in bark beetle outbreak conditions. 
$\mathrm{BF}$, as the strongest pheromone source, attracted most spruce bark beetles and obtained the highest relative and absolute catch of females. The BM mixture, which was combined with it as the weakest pheromone source, achieved the highest absolute and relative male catch. Although males did not favor BM in this combination statistically significantly, it can still be said that they preferred a weaker (weakest overall) pheromone source. In contrast, females statistically significantly favored the strongest BF mixture when assessing relative catch.

When combining combination BM with a moderate source of SL, females, in absolute as well as relative capture, favored a moderate source (SL), while males preferred the weakest source (BM), although, in either case the difference was not statistically significant. The balanced capture of both sexes together, although the SL mixture was a stronger pheromone source, was probably due to the higher content and another ratio of primary attractants $(-)$ - $\alpha$-pinene and $(+)$-limonene in BM (BLAŽENEC and JAKUŠ, 2009).

The properties of individual mixtures were also reflected in the overall catch of the barriers. The highest absolute and relative capture of females and males was obtained with the BM-BF barrier. This confirmed the combination of the weakest and strongest pheromone source to ensure maximum trapping of the barrier and, at the same time, the appropriate sex ratio (JAKUš and Šimko, 2000; JAKUŠ and BLAŽENEC, 2002; JAKUš and BlAŽENEC, 2003; BLAŽENEC and JAKUŠ, 2009). The other two barriers in which the BM mixture (BM-SL, BM-IT) were combined achieved approximately the same absolute and relative capture of male and female. Their capture did not differ statistically significant from each other. The IT-IT control barrier obtained the lowest catch. We recognize that catches of pheromone traps may be influenced by factors other than pheromone mixtures, such as trap design (GALKo et al., 2016), stand edge conditions (MezeI et al., 2011) or environmental conditions (MezEI et al., 2012).

An important indicator of the properties of the individual mixtures was also the dispersion of individual bark beetles around pheromone traps. It indicates how many individuals attracted from a greater distance were not thoroughly attracted or caught in the pheromone trap. The passive traps around the active pheromone traps were used for their detection. We expected greater dispersion around stronger pheromone sources. However, the results are not so clear as the results of pheromone catches.

The highest absolute catch of females was in passive $\mathrm{P}$ (IT) traps adjacent to one of the IT mixtures at the control barrier and of males in passive traps near the mixture SL in the combination of mixtures BM-SL. Passive P (BM) traps, with the exception of the BM-SL combination, had the lowest catches. From these results, the effect of the individual mixtures on the scattering around the active pheromone traps is not clear, but it was probably a greater influence than the individual mixtures had in their mutual combination in barriers. The highest dispersion in the surroundings in the form of absolute capture of both male and female, was detected by the group of passive traps $\mathrm{P}$ (BM-SL) adjacent to the BMSL barrier. It was similar in the evaluation of relative catch, but most females were caught by the group of passive traps $\mathrm{P}(\mathrm{BM}-\mathrm{BF})$. The lowest absolute and relative catch of females was achieved by the group of passive traps $\mathrm{P}$ (BM-IT).

We assumed that males avoiding stronger pheromone sources should be better attracted to traps with weaker pheromone sources, thereby reducing dispersion. However, it is also important to note that the optimized mixtures, and especially their combinations in the barriers, actually caught more sexes together, both females and males, as a control barrier. There was a need to express how much, on one hand, was attracted and trapped by the barrier of pheromone traps, and how much of this amount was still trapped in the surroundings as a scatter. We used the catch percentage indicator in groups of passive traps from trapping in active pheromone traps barriers, thus expressing the trapping efficiency of combinations of mixtures in active traps barriers. The smaller the percentage caught in the group of passive traps, the better the barrier of active traps worked. The lowest percentage of capture of females and males was achieved by the group of passive traps $\mathrm{P}(\mathrm{BM}-\mathrm{BF})$. The second lowest percentage of catching was achieved by the group of passive traps $\mathrm{P}(\mathrm{BM}-\mathrm{IT})$ and the third group of passive traps $\mathrm{P}$ (BM$\mathrm{SL})$. The highest percentage of capture was achieved by the group of passive traps P (IT-IT) adjacent to the control barrier. For the percentage of capture of males, the groups of passive traps did not differ significantly. Only the groups of passive traps P (IT-IT) and P (BM$\mathrm{BF})$ differed statistically in the percentage of females.

According to SCHLYTER (1992), at least 2.5\% of Norway spruce bark beetles are captured in passive traps located within 10 meters of the pheromone source at a source strength of 24 to $240 \mathrm{mg} \mathrm{day}^{-1}$. In the present study, only the group of passive traps at the IT-IT control barrier reached this value, while all other groups of passive traps reached lower values. From this point of view, the optimized combinations of mixtures in the pheromone trap barrier are therefore more efficient, as there are fewer individuals scattered per unit of captured spruce bark beetle.

\section{Conclusion}

We have shown that increasing the efficacy of pheromone trap barriers for I. typographus is possible by altering the pheromone mixture with low levels of cis-Verbenol (cV, targeting males, $\mathrm{BM})$, the mixture with high levels of $\mathrm{cV}$ (targeting females, BF), and the pheromone mixture with intermediate levels of $\mathrm{cV}$ (SL). Furthermore, the results confirm that the performance of the combination of low levels of $\mathrm{cV}$ (targeting males) and high levels of $\mathrm{cV}$ (targeting females) mixtures is complemented by the desired reduced dispersion around the barrier, which reduces the risk of attack on trees in the surroundings. 


\section{Acknowledgements}

This contribution was supported by the project of the Slovak Research and Development Agency under contracts APVV-15-0761, Grant Agency for Science of Slovak Academy of Sciences (2/0176/17) and by grant "Development of integrated modern and innovative diagnostic and protection methods of spruce stands with the use of semiochemicals and methods of molecular biology", No. QK1910480 financed by the Ministry of Agriculture of Czech Republic. The authors wish to thank the firm Fytofarm Ltd. for providing the pheromone baits and pheromone traps and Anka Babicová for help with beetle dissection.

\section{References}

BLAŽENEC, M., JAKUŠ, R., 2009. Effect of (+)-limonene and 1-methoxy-2-propanol on Ips typographus response to pheromone blends. Journal of Forestry Research, 20 (1): 37-44. https://doi.org/10.1007/s11676-009-0008-0

Byers, J.A., 1991. BASIC algorithms for random sampling and treatment randomization. Computers in Biology and Medicine, 21 (1-2): 69-77. https://doi.org/10.1016/00104825(91)90037-A

DiCKens, J.C., 1981. Behavioural and electrophysiological responses of the bark beetle, Ips typographus, to potential pheromone components. Physiological Entomology, 6 (3): 251-261. https://doi.org/10.1111/j.1365-3032.1981. tb00269.x

Galko, J., Nikolov, C., Kunca, A., Vakula, J., GubKa, A., ZÚBRIK, M., RelL, S., KonôPKA, B., 2016. Effectiveness of pheromone traps for the European spruce bark beetle: a comparative study of four commercial products and two new models. Central European Forestry Journal, 62 (4): 207-215. https://doi.org/10.1515/forj-2016-0027

Gossenauer-Marohn, H., 1998. Untersuchungen zum Nachweis der Bedeutung primärer Lockstoffe für die Anlockung des Buchdruckers Ips typographus L. (Coleoptera, Scolytidae) [Investigation to prove the importance of primary attractants in attracting the bark beetle Ips typographus L. (Coleoptera, Scolytidae)]. $\mathrm{PhD}$ thesis. Göttingen: Georg-August-Universität $\mathrm{zu}$ Göttingen. $235 \mathrm{p}$.

JAKUŠ, R., 1998. A method for the protection of spruce stands against Ips typographus by the use of barriers of pheromone traps in north-eastern Slovakia. Anzeiger für Schädlingskunde, Pflanzenschutz, Umweltschutz, 71 (8): 152-158. https://doi.org/10.1007/BF02769004

JAKUŠ, R., BLAŽENEC, M., 2003. Influence of the proportion of (-) $\alpha$-pinene in pheromone bait on Ips typographus (Col., Scolytidae) catch in pheromone trap barriers and in single traps. Journal of Applied Entomology, 127 (2): 91-95. https://doi.org/10.1046/j.1439-0418.2003.00695.x

JaKuš, R., BlažEneC, M., VoJTĚCH, O., 2011. Use of antiattractants in specific conditions of protected areas. Folia Oecologica, 38 (1): 46-51.

JAKUŠ, R., Šimko, J., 2000. The use of dispensers with different release rates at pheromone trap barriers for Ips typographus. Anzeiger für Schädlingskunde, 73 (2): 3336. https://doi.org/10.1046/j.1439-0280.2000.00033.x

Mezei, P., Jakuš, R., Blaženec, M., Belánová, S., Šmídt, J., 2011. Population dynamics of spruce bark beetle in a nature reserve according to stand edges. Folia Oecologica, 38 (1): 73-79.

Mezei, P., Jakuš, R., Blaženec, M., Belánová, S., Šmídt, J., 2012. The relationship between potential solar radiation and spruce bark beetle catches in pheromone traps. Annals of Forest Research, 55 (2): 243-252.

NiEMEYER, H., 1997. Integrated bark beetle control: experiences and problems in Northern Germany. In GrÉGorire, J.C., Liebhold, A.M., Stephen, F.M., DaY, K.P., SAlom, S.M. (eds). Proceedings, integrating cultural tactics into the management of bark beetle and reforestation pests. Vallombrosa, Italy, September 1-3, 1996. General Technical Report NE, 236. Radnor, PA: USDA Forest Service, Northeastern Forest Experiment Station, p. 80-86.

Niemeyer, H., Watzek, G., 1996. Test von Monoterpenen als Zusatz zu PheropraX ${ }^{\circledR}$ bzw. ChalcopraX ${ }^{\circledR}$ in Pheromonfallen zum Fang des Buchdruckers, Ips typographus L. bzw. des Kupferstechers, Pityogenes chalcographus L. (Col., Scolytidae) [Experiments on monoterpenes in combination with Pheroprax ${ }^{\circledR}$ and Chalcoprax ${ }^{\circledR}$ in pheromone traps for catching the bark beetles Ips typographus L. and Pityogenes chalcographus L. (Col., Scolytidae)]. Anzeiger für Schädlingskunde, Pflanzenschutz, Umweltschutz, 69 (5): 109-110. https:// doi.org/10.1007/BF01996880

Reddemann, J., Schopf, R., 1996. Zur Bedeutung von Monoterpenen bei der Aggregation des Buchdruckers Ips typographus (Coleoptera: Scolytidae: Ipinae) [The importance of monoterpenes in the Aggregation of the spruce bark beetle Ips typographus (Coleoptera: Scolytidae: Ipinae)]. Entomologia Generalis, 21 (1-2): 69-80. https://doi.org/10.1127/entom.gen/21/1996/69

Seidl R., Müller, J., Hothorn, T., Bässler, C., Heurich, M., Kautz, M., 2016. Small beetle, large-scale drivers: how regional and landscape factors affect outbreaks of the European spruce bark beetle. Journal of Applied Ecology, 53 (2): 530-540. https://doi.org/10.1111/13652664.12540

Schiebe, C., BlažEnec, M., JaKuš, R., Unelius, C.R., Schlyter, F., 2011. Semiochemical diversity diverts bark beetle attacks from Norway spruce edges. Journal of Applied Entomology, 135 (10): 726-737. https://doi. org/10.1111/j.1439-0418.2011.01624.x

Schiebe, C., Unelius, C.R., Ganji, S., Binyameen, M., Birgersson, G., Schlyter, F., 2019. Styrene, (+)-trans$(1 \mathrm{R}, 4 \mathrm{~S}, 5 \mathrm{~S})-4-$ Thujanol and oxygenated monoterpenes related to host stress Elicit strong electrophysiological responses in the bark beetle Ips typographus. Journal of Chemical Ecology, 45: 474-489. https://doi.org/10.1007/ s10886-019-01070-8

Schlyter, F., Byers, J.A., LöfQvist, J., 1987a. Attraction to pheromone sources of different quantity, quality, and spacing: density-regulation mechanisms in bark beetle Ips typographus. Journal of Chemical Ecology, 13 (6): 1503-1523. https://doi.org/10.1007/BF01012294 
SCHLYTER, F., LÖFQUIST, J., BAYERS, J.A., 1987b. Behavioural sequence in the attraction of the bark beetle Ips typographus to pheromone sources. Physiological Entomology, 12 (2): 185-196. https://doi.org/10.1111/j.1365-3032.1987. tb00741.x

SChlyter, F., 1992. Sampling range, attraction range, and effective attraction radius: estimates of trap efficiency and communication distance in coleopteran pheromone and host attractant systems. Journal of Applied Entomology, 114 (1-5): 439-454. https://doi. org/10.1111/j.1439-0418.1992.tb01150.x

UNDERWOOD A.J., 2001. Experiments in ecology. Their logical design and interpretation using analysis of variance. Cambridge: Cambridge University Press. 500 p. https://doi.org/10.1017/CBO9780511806407

VARKONDA, Š. 1996. Feromónový odparník, priemyselný vzor 5720, Úrad priemyselného vlastníctva Českej republiky [Pheromone dispenser, Industrial pattern 5720, Office of industrial ownership of the Czech Republic].
VAupel, O., DubBel, V., 1985. Untersuchung zur Optimierung von Fangsystemen zur Verbesserung des Massenfanges beim Buchdrucker (Ips typographus L.) [Investigation to optimize trapping systems for improving mass trapping of the spruce bark beetle (Ips typographus L.)]. Zeitschrift für Angewandte Entomologie, 99 (1-5): 52-59. https:// doi.org/10.1111/j.1439-0418.1985.tb01959.x

ViTÉ, J.P., 1989. The European struggle to control Ips typographus: past, present and future. Ecography, 12 (4): 520-525. https://doi.org/10.1111/j.1600-0587.1989. tb00931.x

Zahradníkoví, M., Zahradník, P., 2017. The influence of evaporated pheromone upon the trapping of the spruce bark beetle - Ips typographus (L.) (Coleoptera: Curculionidae: Scolytinae) - Short communication. Journal of Forest Science, 63: 149-152. https://doi. org/10.17221/1/2016-JFS

Received July 3, 2020 Accepted November 3, 2020 